\title{
Competitive Adsorption of Chloroform and Bromoform Using Commercial Bituminous and Coconut Based Granular Activated Carbons
}

\author{
Zinabu Tebeje \\ Haramaya University, Faculty of Engineering, P O Box 138, Dire Dawa, Ethiopia. E-mail: Zinabut@yahoo.com
}

\begin{abstract}
A study was made to compare efficiency and capacity of two types of granular activated carbon (GAC), Calgon F200 and Norit GCN1240, for removal of Trihalomethanes (THMs) in water and to examine the competition of one adsorbate in the presence of another. Coconut based Norit (GCN1240) and bituminous based Calgon F200 GACs were selected for the study. Multi-component adsorption isotherm models were established for both GACs using same model water containing chloroform (2.54 mg L$\left.)^{-1}\right)$ and bromoform (1 mg $\left.\mathrm{L}^{-1}\right)$. After sample bottles were agitated at the speed of $25 \mathrm{rpm}$ in a mechanical shaker for 15 days, measurements were taken using gas chromatography. The results obtained were checked with Freundlich adsorption isotherm model. This model expresses well adsorption of one THM species in the presence of another with $\mathrm{R}^{2}>0.95$. Based on the model, adsorption capacity of Calgon F200 and Norit GCN1240 were found higher for bromoform than chloroform. Calgon F200 showed a higher adsorption capacity compared to Norit GCN1240 for a lower equilibrium concentration $\left(<3 \mu \mathrm{g} \mathrm{L} \mathrm{L}^{-1}\right)$. However, for equilibrium concentrations in the range of $3-200 \mu \mathrm{g} \mathrm{L}^{-1}$, both Calgon F200 and Norit GCN1240 showed similar capacity for competitive adsorption of THMs.
\end{abstract}

Keywords: Granular Activated Carbon; Adsorption; Bromoform; Chloroform; Trihalomethane

\section{Introduction}

In 1974, researchers in the Netherlands and the United States demonstrated that trihalomethanes (THMs) were being formed from the interaction of chlorine/bromide with various organic substances in water (Al-Naseri, and Abbas, 2009; USEPA, 1996). These chlorinated organic compounds potentially cause cancer, miscarriages and are mutagenic. Studies also linked these THMs to heart, lung, kidney, liver, and central nervous system damage (Fearing et al., 2004; Edward, 2005). Hence, removal of THMs is necessary and it is achieved mostly by applying GAC filtration (Qasim et al., 2000; Fearing et al., 2004; Edward, 2005). For example, the United States Environmental Protection Agency (USEPA) allows an upper limit of 40 $\mu \mathrm{g} \mathrm{L} \mathrm{L}^{-1}$ THMs in water (USEPA, 1996).

A study was made for adsorption of the most common species of THMs, chloroform and bromoform. Two types of GAC from different manufacturers and base materials, coconut based Norit (GCN1240) and bituminous based Calgon F200, were selected. The selected GACs were recommended by their manufacturers for best adsorption of THMs regardless of the difference in origin of base material. Hence, the study was done to determine the adsorption capacity of the two GACs to determine and compare removal efficiencies. Beside, the competitive adsorption of one THM species in the presence of the other was investigated.

Design of full scale GAC adsorption process involved time consuming and expensive pilot plant studies. Batch adsorption isotherm tests were conducted to predict the breakthrough of THMs removal from water by different types of GAC and to know the result in a short time (15 days) instead of months time pilot study (Crittenden et al., 1986; McGuire, 1991). Previous researches have been done for the adsorption capacity determination of GAC for single THM species but not the competitive adsorption of one species in the presence of the other.
Thus, this study was initiated with the objectives to (1) establish Freundlich competitive adsorption isotherms for chloroform and bromoform, (2) determine the capacity of each of the two commercially available GACs (Calgon F200 and Norit GCN1240) for competitive adsorption of one THM species in the presence of another, and (3) compare competitive adsorption of THM species on Bituminous and Coconut GACs.

\section{Material and Methods}

\subsection{Experimental Setup and Operational Procedure} 2.1.1. Model Water Preparation

For batch adsorption isotherm, model water was prepared batchwise in 10.521 brown glass bottle from deionized water. One mmole of $\mathrm{NaHCO}_{3}$ and the target contaminant chloroform $\left(2.54 \mathrm{mg} \mathrm{L}^{-1}\right)$ and bromoform (1 $\left.\mathrm{mg} \mathrm{L}^{-1}\right)$ were added to the bottles. Then, the glass bottle was covered by parafilm to avoid air formation at the top of the bottle and mechanically stirred for one day to achieve complete mixing.

\subsubsection{Powdered Granular Activated Carbon (PGAC) Preparation}

The grain size of GAC used in batch experiments was $200 \times 400$ mesh $(74 \mu \mathrm{m} \times 37 \mu \mathrm{m})$. This size was obtained by crushing 12 × 40 mesh $(1680 \mu \mathrm{m}$ x $420 \mu \mathrm{m})$ GAC supplied by Calgon (Chemivron carbon, Pittsburg, USA) and Norit (Norit, Amersfoort, The Netherlands). After GAC grains were crushed, the appropriate size for batch was achieved by sieving on 200 x 400 mesh (passing 200 mesh sieve and retained on 400 mesh sieve). The GAC grains that did not pass the upper sieve were returned and crushed again until it passed the sieve. GAC grains of appropriate size were stored in a beaker covered with aluminum foil. Fines produced during crushing and sieving were removed by washing. Then, GAC of appropriate size was stored in a clean beaker filled with 
de-ionized water. The GAC was stirred with a glass rod and allowed to settle. After the GAC particles settled in one to three minutes, the supernatant was poured off and new de-ionized water was added. The stirring and settling was continued using fresh de-ionized water until clear supernatant was achieved. The wet GAC was placed in an oven at $105^{\circ} \mathrm{C}$ for two days. The dried GAC was stored in a dark amber bottle with teflon lined caps in a decicator (vacuum sealed glass).

\subsubsection{Batch Experimental Setup}

Batch experiment was conducted to investigate GAC removal capacity of THMs. Model water was prepared using bromoform and chloroform. Powdered granular activated carbon (PGAC $200 \times 400$ mesh size) was used in batch adsorption experiments to reduce the time necessary to reach equilibrium and to ensure a representative carbon samples.

Glass bottles of $314-318 \mathrm{ml}$ volume were stored in 0.5 $\mathrm{M}$ hydrochloric acid $(\mathrm{HCl})$ for two days and cleaned with de-ionized water. Different value of PGAC dosages in the range from 0.02 to $8 \mathrm{~g}$ were introduced to $16 \mathrm{batch}$ reactor bottles (seven reactor bottles for Calgon F200 GAC, seven for Norit GCN1240 and two blanks). These bottles (314-318 ml) were subsequently filled with model water followed by $\mathrm{pH}$ adjustment of $7.0 \pm 0.2$ by adding 1.0 and $0.1 \mathrm{M} \mathrm{HCl}$ using METROHM-691 pH meter. Once the $\mathrm{pH}$ was adjusted, the bottles were covered with double layer parafilm to make air free surface before closing the cap. Then, the bottles were placed on the mechanical shaker and shaken at speed of $25 \mathrm{rpm}$ for 15 days. This contact time was ample to achieve equilibrium in the system for all the THM components studied. After 15 days of adsorption, samples were taken and measured.

\subsection{Analytical Methods \\ 2.2.1. Gas Chromatography}

Gas chromatography (GC) method use headspace for the determination of volatile halogenated hydrocarbons in the samples. Chloroform was detected by an electron capture detector (ECD). Identification was based on retention time while quantification is based on the intensity of the ECD signal using a five-point calibration.

During sample preparation $5 \mathrm{ml}$ of sample using pipette was added into a $20 \mathrm{~mL}$ headspace vial and the vial was closed with a crimp cap with a silicon septum. The sample was heated in a closed headspace vial in order to obtain equilibrium between the concentration of the volatile halogenated hydrocarbons in the headspace above the sample and the concentration in the sample. By purging the headspace with Helium, the volatile hydrocarbons in the headspace were transferred to the GC where they were separated. The components were detected by an ECD and calibration curve and control standards were observed using software (Turbochrom). Identification was based on retention time (5.26 minutes and 11.16 minutes for chloroform and bromoform respectively) while quantification was based on the intensity of the ECD-signal using a five-point calibration. These retention times slightly vary due to aging of the column and were corrected. The quantification of the components was done automatically by the software using linear regression of the second order. Finally results

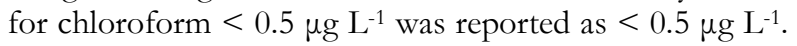
When the total THM result was $<2 \mu \mathrm{g} \mathrm{L^{-1 }}$, the sum of the THMs was reported as $<2 \mu \mathrm{g} \mathrm{L^{-1 }}$. But, when the result of one of the components was $>50 \mu \mathrm{g} \mathrm{L}^{-1}$, the samples were diluted and re-analyzed.

\subsection{Data Analysis}

Among Freundlich and Langmuir adsorption isotherms, the Langmuir adsorption isotherm is based on the theoretical principle of ideal localized monolayer model where only a single adsorption layer exists. Whereas, the Freundlich adsorption isotherm equations is commonly used for adsorption capacity calculations and this equation is accepted as a standard and is strictly an empirical approach used to describe data for adsorbents such as activated carbon (Roy, 1995; Qasim et al., 2000; Crittenden et al., 2005). Liquid phase isotherms are generally interpreted using the empirical Freundlich equation, which relates the amount of impurity in the solution phase to that in the adsorbed phase. The results were interpreted using Freundlich adsorption isotherm equation. The Freundlich Adsorption Isotherm is expressed as:

$$
q_{e}=K C_{e^{n}}^{\frac{1}{n}}
$$

where $q_{\mathrm{e}}\left(\mathrm{mg} \mathrm{g}^{-1}\right)$ represents the amount of THM adsorbed (mg) per unit mass of GAC (g), Ce $\left(\mathrm{mg} \mathrm{L}^{-1}\right)$ is the concentration of residual in contaminated water after the GAC and the contaminated water reach adsorptive equilibrium. K $\left[\left(\begin{array}{ll}m g & g^{-1}\end{array}\right)\left(\begin{array}{ll}L & \mathrm{mg}^{-1}\end{array}\right)^{1 / n}\right]$ is Freundlich adsorption capacity parameter and $1 / \mathrm{n}$ (unit less) is Freundlich adsorption intensity parameter for each sample tested (Qasim et al., 2000; Crittenden et al., 2005).

For fixed values of $C e$ and $1 / n$, the larger the $K$ value the higher is the adsorptive capacity (qe). For fixed values of $\mathrm{K}$ and $\mathrm{Ce}$, on the other hand, the smaller the value of $1 / n$ the lesser would be the concentration dependence of adsorption (Ce). Conversely, if the value of $1 / \mathrm{n}$ is large, the adsorption bond is weak and the value of qe changes distinctly with small changes in Ce.

\section{Results and Discussion}

\subsection{Batch Isotherm Study}

Batch isotherm experiments with PGAC media were carried out with model water containing chloroform and bromoform to examine the effectiveness and adsorption capacity of two GACs (Calgon F200 and Norit GCN1240) produced by two suppliers (Calgon and Norit) for THM removal. In addition, multi-component adsorption isotherms were established to examine the competition of one adsorbate in the presence of another and to compare capacity of bituminous and coconut based GACs. 
Zinabu Tebeje

3.1.1. Competitive Adsorption of Chloroform in the presence of Bromoform

Multi-component adsorption isotherms were established for the two GACs with the same model water containing $2.53 \mathrm{mg}$ chloroform/L and $1.0 \mathrm{mg}$ bromoform/L. Data obtained for chloroform and bromoform fitted well the Freundlich isotherm model and the adsorption is favorable $(1 / \mathrm{n}<1)$. The determined Freundlich adsorption isotherm coefficients namely capacity coefficient $(K)$ and strength $(1 / n)$ of multi-component isotherm for chloroform in the presence of bromoform is shown in (Table 1). The GACs showed very similar adsorption capacities for chloroform equilibrium concentrations in the ranges from $50 \mu \mathrm{g} \mathrm{L} \mathrm{L}^{-1}$ to $500 \mu \mathrm{g} \mathrm{\textrm {L } ^ { - 1 }}$.
Competitive Adsorption of Chloroform and Bromoform

However, for lower equilibrium concentration below 50 $\mu \mathrm{g} \mathrm{\textrm {L } ^ { - 1 }}$ Calgon F200 showed a higher adsorption capacity in comparison to Norit GCN1240. For higher chloroform equilibrium concentrations (>500 $\mu \mathrm{g} \mathrm{\textrm {L } ^ { - 1 }}$ ), Norit GCN1240 showed a higher adsorption capacity in comparison to Calgon F200 (Figure 1). Conversely, the value of $1 / \mathrm{n}$ is large for Norit GCN1240 in comparison to Calgon F200. This implies that Norit GCN1240 has weak adsorption bond toward chloroform and the adsorption capacity (qe) changes distinctly with small changes in equilibrium concentration (Ce) in comparison to Calgon F200.

Table 1. Freundlich isotherm coefficients for competitive adsorption of chloroform and bromoform on Calgon F200 and Norit GCN1240 GAC.

\begin{tabular}{lllll}
\hline & THM species & Competing species & $\mathrm{K}\left[\left(\mathrm{mg} \mathrm{g}^{-1}\right)\left(\mathrm{L} \mathrm{mg}^{-1}\right)^{1 / \mathrm{n}}\right]$ & $1 / \mathrm{n}$ \\
\hline Calgon F200 & Bromoform $\left(\mathrm{Co}=1 \mathrm{mg} \mathrm{L}^{-1}\right)$ & Chloroform $\left(\mathrm{Co}=2.53 \mathrm{mg} \mathrm{L}^{-1}\right)$ & 90.87 & 0.71 \\
Norit GCN1240 & Bromoform $\left(\mathrm{Co}=1 \mathrm{mg} \mathrm{L}^{-1}\right)$ & Chloroform $\left(\mathrm{Co}=2.53 \mathrm{mg} \mathrm{L}^{-1}\right)$ & 138.56 & 0.91 \\
Calgon F200 & Chloroform $\left(\mathrm{Co}=2.53 \mathrm{mg} \mathrm{L}^{-1}\right)$ & Bromoform $\left(\mathrm{Co}=1 \mathrm{mg} \mathrm{L}^{-1}\right)$ & 16.72 & 0.62 \\
Norit GCN1240 & Chloroform $\left(\mathrm{Co}=2.53 \mathrm{mg} \mathrm{L}^{-1}\right)$ & Bromoform $\left(\mathrm{Co}=1 \mathrm{mg} \mathrm{L}^{-1}\right)$ & 18.78 & 0.75 \\
\hline
\end{tabular}

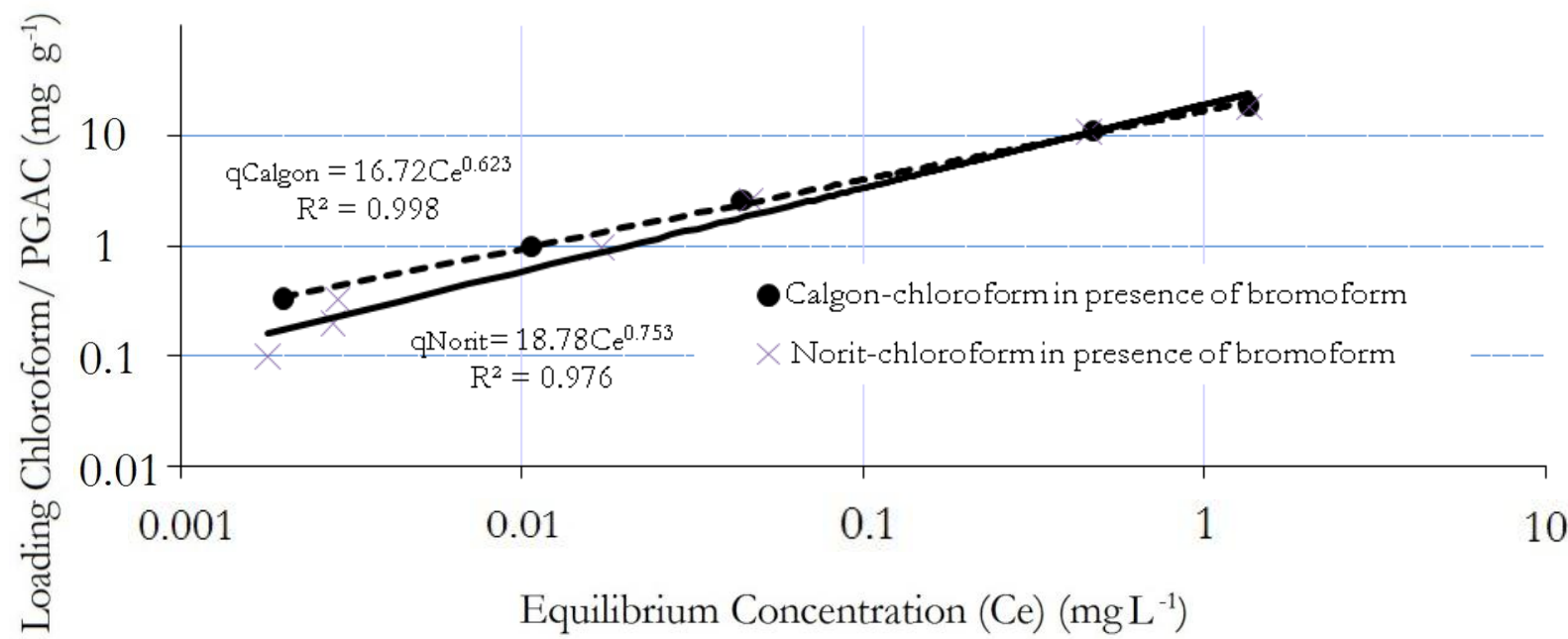

Figure 1. Competitive adsorption isotherm of chloroform in the presence of bromoform. Calgon F200 and Norit GCN1240, PGAC $200 \times 400$ mesh; model water: deionized water with initial concentration Co $=2.35 \mathrm{mg} \mathrm{L}^{-1}$ of chloroform, and Co $=$ $1.00 \mathrm{mg} \mathrm{L}^{-1}$ of bromoform, $\mathrm{pH} 7.0 \pm 0.2, \mathrm{~T}=20^{\circ} \mathrm{C}$.

3.1.2. Competitive Adsorption of Bromoform in the presence of Chloroform

On the other hand competitive batch adsorption isotherms for bromoform in the presence of chloroform were established for Calgon F200 and Norit GCN1240. The GACs showed very similar adsorption capacities for chloroform equilibrium concentrations more than $2 \mu \mathrm{g}$ $\mathrm{L}^{-1}$. However, for lower equilibrium concentration below $2 \mu \mathrm{g} \mathrm{L} \mathrm{L}^{-1}$, Calgon F200 showed a higher adsorption capacity in comparison to Norit GCN1240. For higher chloroform equilibrium concentrations more than $100 \mu \mathrm{g}$ $\mathrm{L}^{-1}$, as per the trend line, Norit GCN1240 showed a higher adsorption capacity in comparison to Calgon F200 (Figure 2). Conversely, the value of $1 / \mathrm{n}$ is large for Norit GCN1240 in comparison to Calgon F200. This implies that Norit GCN1240 has weak adsorption bond toward chloroform and the adsorption capacity (qe) changes distinctly with small changes in equilibrium concentration (Ce) in comparison to Calgon F200. 


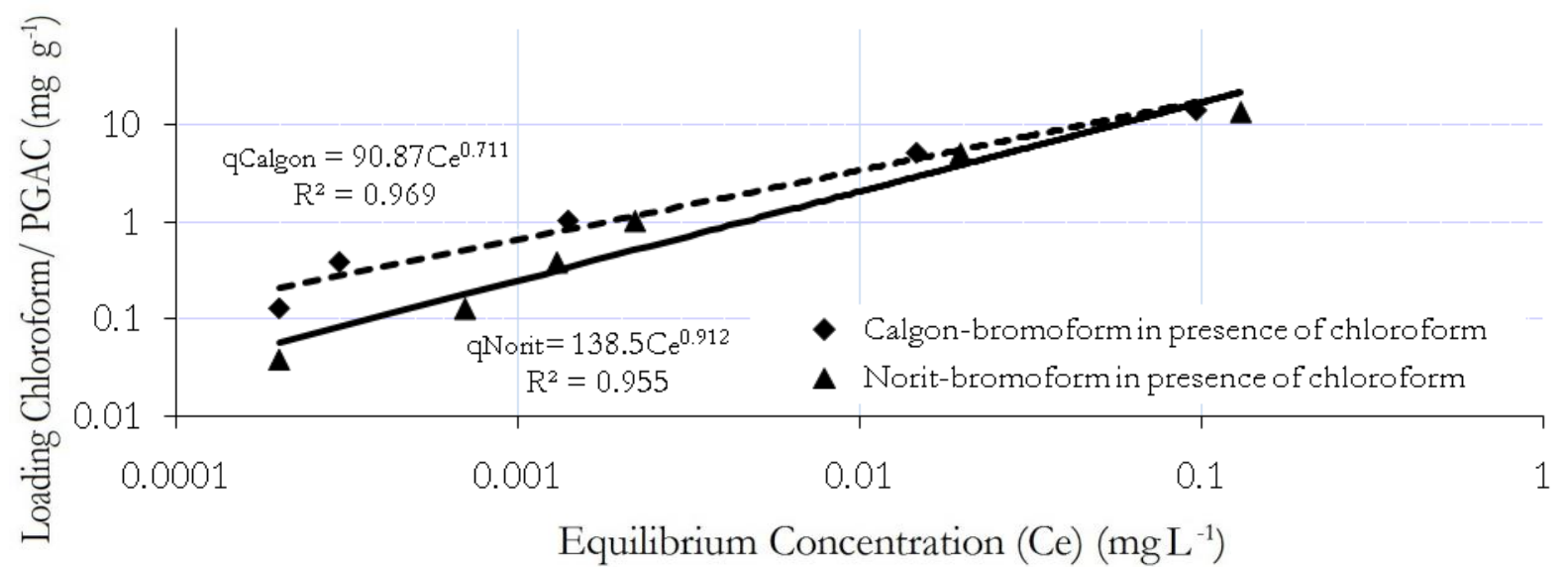

Figure 2. Competitive adsorption isotherm of bromoform in the presence of chloroform. Calgon F200 and Norit GCN1240, PGAC $200 \times 400$ mesh; model water: deionized water with initial concentration Co $=2.35 \mathrm{mg} \mathrm{L}^{-1}$ of chloroform, and Co $=$ $1.00 \mathrm{mg} \mathrm{L}^{-1}$ of bromoform, $\mathrm{pH} 7.0 \pm 0.2, \mathrm{~T}=20^{\circ} \mathrm{C}$.

\subsubsection{Adsorption Comparison of Calgon F200 and Norit GCN1240}

In general, the result showed that Calgon F200 has higher capacity for bromoform and chloroform at lower equilibrium concentration (Figure 3). At a higher equilibrium concentration both GACs show more or less same adsorption capacity though the trend line shows slight increase of adsorption capacity for Norit GCN1240. Results compared for chloroform and bromoform adsorption on the two GACs showed that both had higher affinity for bromoform than chloroform as shown in Figure 3 and Table 1 . The value of $1 / \mathrm{n}$ for bromoform is higher than for chloroform for both Calgon and Norit GACs. This indicates that bromoform has a higher sensitivity towards the equilibrium concentration than chloroform. In general, Norit GCN1240 showed higher $1 / \mathrm{n}$ for both competitive adsorption of bromoform and chloroform implying Norit GCN1240's adsorption capacity (amount of solute adsorbed per unit mass of adsorbent) changes more distinctly with small changes in equilibrium concentration than adsorption capacity ( $\mathrm{q}_{\mathrm{e}}$ ) of Calgon F200 (Figure 3).

Even though Norit GCN1240 has high surface area and Iodine number (Table 2), the adsorption capacity of the two GACs showed similar results. This could be attributed to the presence of a narrow porosity which usually is desirable for adsorbent material intended for the removal of organic mater from solution. Micropores provide high surface area to the GAC. Organic matters are adsorbed preferentially in smaller pores where interaction energies are enhanced due to overlapping adsorption potentials of the surrounding pore walls. However, adsorption of organic compounds from solution is significantly reduced when the pore width is less than $1.5-2.0$ times the diameter of the adsorbate molecule (Li et al., 1997; Liu et al., 2007). Chloroform has a hydraulic radius of $51 \mathrm{~nm}$ (Peesan et al., 2006). This high hydraulic radius might also reduce the adsorption of chloroform in smaller micropores (Liu et al., 2007).

Table 2. Specifications and general characteristics of the granular activated carbons (GACs) used (EOCCC, 2003; NAC, 2004).

\begin{tabular}{llll}
\hline Supplier & Unit & Norit & Calgon \\
\hline GAC name & - & Norit GCN1240 & Calgon F200 \\
Iodine number & - & 1050 & 850 \\
Total surface area (B.E.T.) & $\mathrm{m}^{2} \mathrm{~g}^{-1}$ & 1150 & 850 \\
Apparent density & $\mathrm{kg} \mathrm{m}^{-3}$ & 510 & - \\
Ball-pan hardness & - & 99 & 95 \\
Effective size D10 & $\mathrm{Mm}$ & $0.6-0.7$ & $0.6-0.8$ \\
Uniformity coefficient & - & 1.9 & 1.7 \\
\hline
\end{tabular}




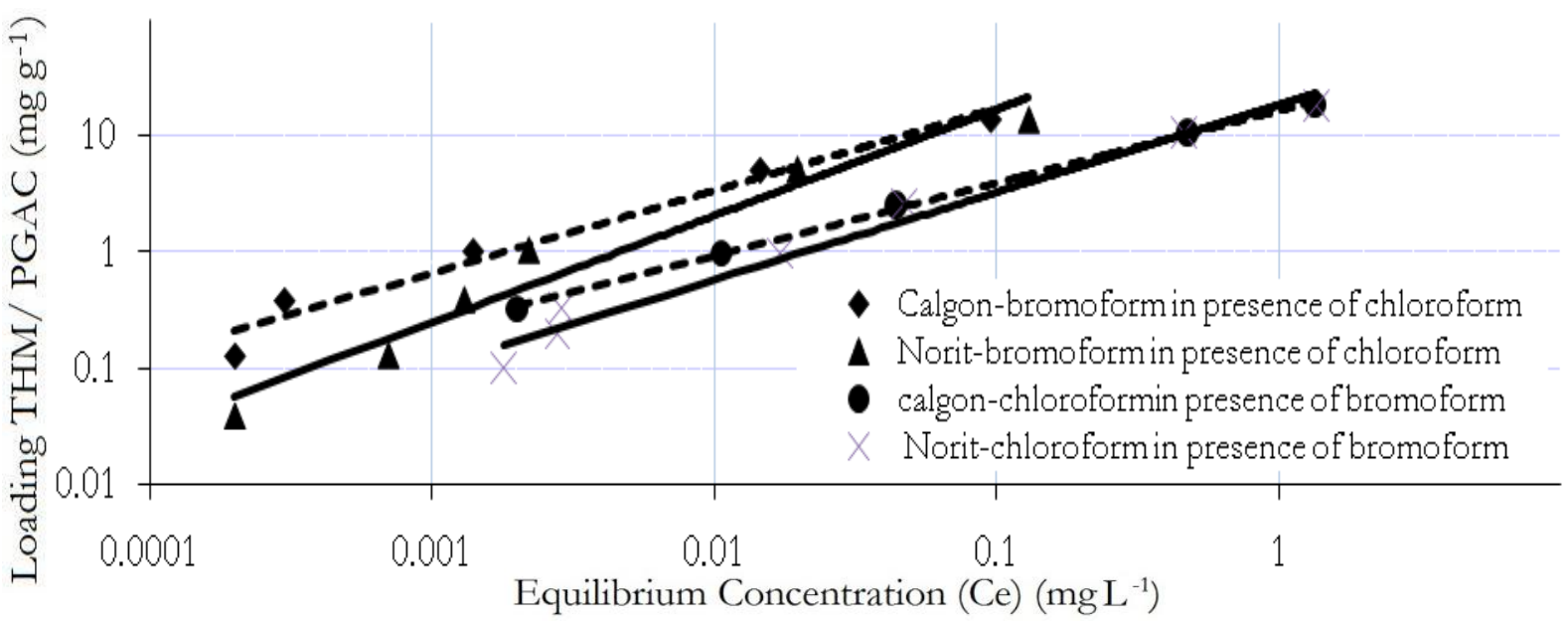

Figure 3. Freundlich adsorption isotherm for bromoform and chloroform adsorption on. Calgone F200 and Norit GCN1240, PGAC 200 x 400 mesh; model water: deionized water with initial concentration Co $=2.35 \mathrm{mg} \mathrm{L}^{-1}$ chloroform, and Co $=1.00$ $\mathrm{mg} \mathrm{L} \mathrm{L}^{-1}$ bromoform, $\mathrm{pH}$ of $7.0 \pm 0.2, \mathrm{~T}=20^{\circ} \mathrm{C}$.

\section{Conclusions}

Results from batch adsorption experiment conducted with model water containing bromoform and chloroform using Calgon F200 and Norit GCN1240 GACs fitted well the Freundlich adsorption isotherm. Batch adsorption isotherm model for both Calgon F200 and Norit GCN1240 demonstrated that THMs can be effectively adsorbed and showed much higher capacity for bromoform in comparison to chloroform. Besides, competitive batch adsorption isotherms established for bromoform and chloroform with Calgon F200 and Norit GCN1240 showed very similar adsorption capacities for equilibrium concentrations in the range from $3 \mu \mathrm{g} \mathrm{L} \mathrm{L}^{-1}$ to $200 \mu \mathrm{g} \mathrm{L} \mathrm{L}^{-1}$. However, for lower concentration below $3 \mu \mathrm{g}$ $\mathrm{L}^{-1}$ Calgon F200 showed a higher adsorption capacity in comparison to Norit GCN1240.

\section{Acknowledgments}

My first intellectual debt is to Professor Gary Amy, Dr. B. Petruseviski, Dr. K. Ghebremichael for helping me to consider different, more interesting analytical and methodological insights. I would like to thank the editors also for their wise questions and constructive critiques which rendered this study readable and acceptable piece of work. I am particularly indebted to my wife Melat G. for the important role she plays and her keen cooperation when it was needed. I thank UNESCO-IHE, Coca-Cola Company for its generous financial supports and Haramaya University.

\section{References}

Al-Naseri, S. K. and Abbas, T. R. 2009. Predicting NOM removal by fixed-bed GAC adsorbers. Jordan Journal of Civil Engineering 3(2): 172-183.

Crittenden, J.C., Trussell, R.R., Hand, D.W., Howe, K.J. and Tchobanoglous, G. 2005. Water Treatment:
Principles and Design. $2^{\text {nd }}$ edition. John Wiley and Sons, Inc., USA.

Crittenden, J.C., Berrigan, J.K., and Hand, D.W. 1986. Design of rapid small scale adsorption test for a constant diffusivity. Water Pollution Control Federation 58(4): 312-319.

EOCCC (European Operations of Calgon Carbon Corporation). 2003. Technologies for purification, Separation, Recovery and Synthesis. Bulletin No. W2050. Feluy, Belgium. (http://www.chemvironcarbon.com) (Accessed on March 10, 2010)

Edward, E.B. 2005. Water Treatment Plant Design. $4^{\text {th }}$ edition. Mc-Graw Hill Publishing Company, New York.

Fearing, D.A., Banks, J., Wilson, D., Hillis, P.H., Campbell, A.T. and Parsons, S.A. 2004. NOM control options: the next generation. Water Science and Technology: Water Supply 4(4): 139-145.

Li, j.W., Yu, Z., Gao, M. and Cai, X. 1997. Trihalomethanes adsorption on activated carbon fiber and granular activated carbon. Water, Air and Soil Pollution 97: 367-378.

Liu, X., Yu, G. and Han, W. 2007. Granular activated carbon adsorption and microwave regeneration for the treatment of 2,4,5-trichlorobiphenyl in simulated soil-washing solution. Journal of Hazardous Materials 147: 746-751.

McGuire, M. 1991. Evaluating GAC for trihalomethanes control. Journal of American Water Works 83: 38-48.

NAC (Norit Activated Carbon). 2004. Material safety data sheet. Report No. 2201/01. Amersfoort, The Netherlands (http://www.norit-ac.com) (Accessed on February 12, 2010)

Peesan, M., Sirivat, A., Supaphol, P. and Rujiravanit, R. 2006. Dilute solution properties of hexanoyl chitosan in chloroform, dichloromethane, and 
Zinabu Tebeje tetrahydrofuran. Journal of Applied Science 100: 45154525

Qasim, S.R., Motley, E.M. and Zhu, G. 2000. Water Works Engineering: Planning, Design, and Operation. PrenticeHall PTR, Upper Saddle River, NJ.

Roy, G.M. 1995. Activated Carbon Applications in the Food Pharmacentical Industries. Technomic Publishing Company, Inc., Lancaster, Pennsylvania, USA.
East African Journal of Sciences Volume 4 (2) 59-64

USEPA (United States Environmental Protection Agency). 1996. ICR Manual for Bench and Pilot Scale Treatment Studies. Report No. EPA 814/B-96003. USA. 